\title{
Iliac Lymphadenectomy following Intrauterine Mapping in a Female Dog with Breast Neoplasm
}

\author{
João Pedro Scussel Feranti ${ }^{1,2}$, Gabriela Pesamosca Coradini ${ }^{2}$, Marcella Teixeira Linhares ${ }^{2}$, \\ Hellen Fialho Hartmann², Rammy Vargas Campos ${ }^{2}$, Marília Teresa de Oliveira ${ }^{3}$, \\ Rafael Oliveira Chaves', Álvaro José Chávez Silva ${ }^{2,4}$ \& Maurício Veloso Brun ${ }^{5}$
}

\begin{abstract}
Background: The lymphatic system plays an important role in the local control of neoplasms as well as in the transportation of tumor cells, which represents the most common pathway of metastasis. From the tumorigenesis, there is a remarkable enlargement of the tumor drainage network towards the regional and target lymph nodes. Since the mammary lymphatic system of animals with neoplasms as well as the demarcation of the pelvic and abdominal caudal chain are poorly studied, the aim of the present study is to report a case of iliac lymphadenectomy after intrauterine lymphatic dyeing in a dog with breast neoplasm, which allowed the identification of metastasis in the medial iliac lymph node.

Case: A 7-year-old, $13.4 \mathrm{~kg}$, non neutered, mixed breed, female dog was diagnosed with ulcerative neoplasm in the left caudal abdominal breast, which presented evolution of approximately 90 days, presenting ulceration for 10 days, according to the tutor. After a clinical evaluation, thoracic radiography and abdominal ultrasonography were requested, which did not present metastasis suggestive images. Therefore, left unilateral total mastectomy was indicated. Retro-umbilical celiotomy was performed for the administration of $0.5 \mathrm{~mL}$ of $1 \%$ intrauterine methylene blue (body of the uterus), which allowed lymphatic mapping and medial iliac lymphadenectomy. Subsequently, ovariohysterectomy was performed and after celiorrhaphy, axillary lymphadenectomy was performed, followed by left unilateral mastectomy and concomitant removal of the superficial inguinal lymph node. The patient had a prompt recovery and was discharged from hospital in six hours postoperatively. The excised material was referred for histopathological examination, which revealed the presence of metastasis of simple tubulopapillary carcinoma of the mammary gland in the left medial and superficial inguinal lymph nodes, while the axillary lymph node had no metastases. At the end of 10 days, the patient was clinically stable, with good healing of the surgical wound. After a 120-day postoperative period, the patient had a good clinical status, with no respiratory alterations, and there was no evidence of metastasis on the chest X-ray as well as abdominal ultrasound.

Discussion: Considering the great occurrence of breast neoplasms, it is important to develop studies on new approaches in the therapeutic management of this condition and sharing of reports as described. The objective of the lymphadenectomy was to evaluate the possible involvement of regional lymph nodes, since, according to the condition of the lymph nodes in the histopathological examination, it appears as an important prognostic factor, seeing that the survival time is less than two years for $85.7 \%$ in dogs with regional lymph node metastases. In animals, there are no studies based on the therapeutic alternative of lymphadenectomy, which is believed to be palliative in the reported patient, due to the fact that it is a tubulopapillary carcinoma with different foci of lymph node metastases. Otherwise, lymphadenectomy enabled a better definition of the prognosis and proved to be an important tool for staging. The use of methylene blue was chosen because it was reportedly used in dogs, with excellent results in sentinel lymph nodes mapping, and due to its ease of obtaining and low cost of application. It is concluded that in canines with breast neoplasms, it is important to perform lymphatic mapping to identify possible metastases in cellular tissues and to delimit regional lymph vessels and lymph nodes, thus facilitating the surgical removal of these structures with safety margins. In addition, it is important to perform lymphadenectomy even to lymph nodes that are not infarcted or present macroscopic changes, given that in this case, it already existed metastasis, even in a lymph node of $4 \mathrm{~mm}$.
\end{abstract}

Keywords: metastasis, sentinel lymph node, lymphatic mapping, mastectomy, canine.

${ }^{1}$ Surgery and Veterinary Clinic Department, University of the Campanha Region (URCAMP), Alegrete, RS, Brazil. ${ }^{2}$ Graduate Program of Veterinary Medicine, Federal University of Santa Maria (UFSM), Santa Maria, RS. ${ }^{3}$ Veterinary Clinics Department, Federal University of Pampa (UNIPAMPA), Uruguaiana, RS. ${ }^{4}$ Animal Welfare Department, National Autonomous University of Nicaragua (UNAN), Leon, Nicaragua. ${ }^{5}$ PPPGMV, UFSM, Santa Maria. CORRESPONDENCE: M.V. Brun [mauriciovelosobrun@ hotmail.com - Tel.: +55 (54) 99962-7707]. Av. Roraima n. 1000, Cidade Universitária. Bairro Camobi. CEP 97105-900 Santa Maria, RS, Brazil. 


\section{INTRODUCTION}

Among the neoplasias in female dogs, those of the mammary gland are the most frequent, representing about 50 to $70 \%$ of the affections of this nature. It is estimated that in Brazil the incidence of malignant tumors exceeds $70 \%$, which may result in the appearance of regional lymph node metastases at the time of diagnosis and sometimes in the pulmonary parenchyma [6].

The lymphatic system plays an important role in the local control of neoplasms and in the transportation of tumor cells, which represents the most common pathway of metastases [5]. From the tumorigenesis, appears lymphangiogenic factors that induce the formation of new lymphatic vessels and enlarge the tumor drainage network to the regional, and target lymph nodes, which makes possible the presence of metastatic cells in lymph nodes distant from the primary neoplasia [13]. Thus, lymphatic mapping with vital dyes becomes an alternative for the identification of sentinel lymph nodes [1].

The mammary lymphatic system of animals with neoplasms has been poorly studied. Also, the demarcation of the pelvic and abdominal caudal chain is not routinely used for identification and removal of microlinphonodes during celiotomies. Due to the above mentioned, the aim of this study is to report a case of iliac lymphadenectomy after intrauterine lymphatic dyeing in a female dog with breast neoplasm, which allowed the identification of metastasis in the medial iliac lymph node.

\section{CASE}

A 7-year-old, $13.4 \mathrm{~kg}$, non-neutered, mixed breed, female dog was diagnosed with ulcerative neoplasm in the left caudal abdominal breast, which presented evolution of approximately 90 days, presenting ulceration for 10 days, according to the tutor. After a clinical evaluation, thoracic radiography and abdominal ultrasonography were requested, which did not present images suggestive of metastasis. Hematological exams for evaluation of the renal and hepatic function, as well as erythrogram and leukogram analysis, were within the reference parameters for the species. Therefore, left unilateral total mastectomy was indicated.

After extensive trichotomy of the operative area and establishment of an adequate anesthetic plane, retro-umbilical celiotomy was performed for the ad- ministration of $0.5 \mathrm{~mL}$ of $1 \%$ intrauterine methylene blue $^{1}$, (body of the uterus); with the aid of an insulin needle coupled in a $1 \mathrm{~mL}$ syringe (Figures $1 \mathrm{~A}$ and $1 \mathrm{~B}$ ). This allowed lymphatic staining and lymphadenectomy of the medial iliac lymph node (Figures 1C and 1D). Subsequently, ovariohysterectomy was performed and after celiorrhaphy, axillary lymphadenectomy was performed, followed by left unilateral mastectomy and concomitant removal of the superficial inguinal lymph node. The patient had a prompt recovery and was discharged from hospital in six hours postoperatively.

The excised material was referred for histopathological examination, which revealed metastasis of simple tubulopapillary carcinoma in the left medial iliac $(4 \mathrm{~mm})$ and superficial inguinal lymph node $(1.2 \mathrm{~cm})$, while the axillary lymph node had no metastases. Upon examination of the mammary chain, it was possible to detect the preservation of margins of neoplasm-free tissue, despite the diagnosis of tubulopapillary carcinoma with presence of neoplastic cells within the lymphatic vessels.

From the results of the tests, chemotherapy with doxorubicin and cyclophosphamide was indicated, but the owner chose not to perform chemotherapy. The patient still had ovarian and parauterine cyst, as well as cystic endometrial hyperplasia, confirmed by histopathological analysis.

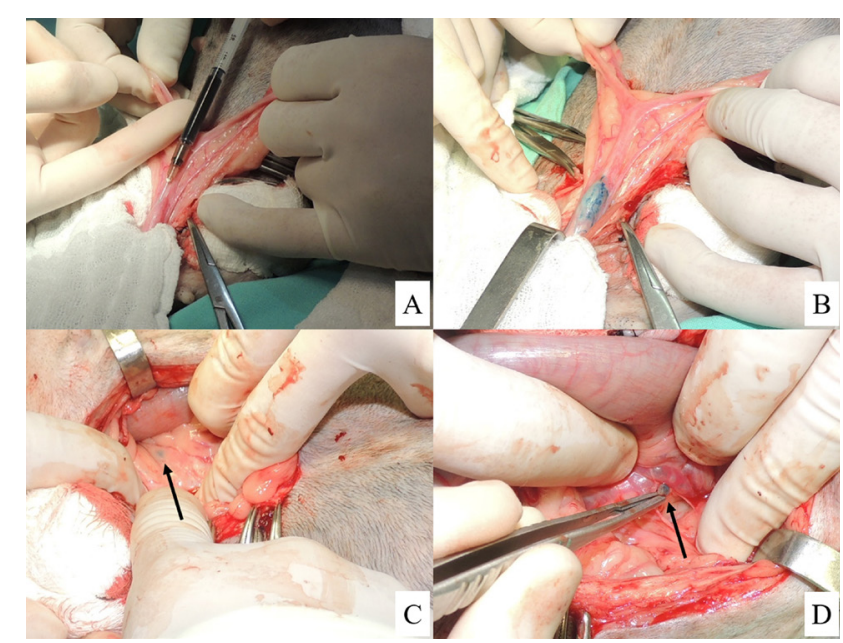

Figure 1. Images of intrauterine lymphatic mapping and lymphadenectomy (medial iliac) of a 7-year-old, $13.4 \mathrm{~kg}$, female canine. A- Exposure of uterine body for insertion of insulin needle coupled in a $1 \mathrm{ml}$ syringe for intraparenchymal administration of $1 \%$ methylene blue. B- Uterine mapping with $1 \%$ methylene blue after intraparenchymal intrauterine administration. C-Visualization of the medial iliac lymph node (arrow), located laterally to the ureter and descending colon, after staining with $1 \%$ methylene blue. D- Clear lymphatic mapping with $1 \%$ methylene blue of the non-infarcted medial iliac lymph node (arrow) after dissection. 
At the end of 10 days, the patient was clinically stable, with good healing of the surgical wound. After a 120-day postoperative period, the patient had a good clinical status, with no respiratory alterations, and there was no evidence of metastasis on the chest $\mathrm{X}$-ray as well as abdominal ultrasound.

\section{DISCUSSION}

Considering the great occurrence of breast neoplasms, it is important to develop studies based on new approaches in the therapeutic management of this condition. As well as to share the findings through reports; such as the one described here in which iliac, axillary and inguinal lymphadenectomies were performed, associated with mastectomy and ovariohysterectomy, which had not previously been documented in small animals according to the literature.

The objective of the lymphadenectomy was to evaluate the possible involvement of regional lymph nodes, since, according to Karayannopoulou [9], the lymph node condition in histopathological examination is an important prognostic factor, given that the survival time is less than two years for $85,7 \%$ of dogs with regional lymph node metastases.

As for human prostate cancer, pelvic lymphadenectomy is considered the most accurate staging procedure, being suggested in some studies this therapeutic alternative, but still with inconsistent data $[2,4,17]$. In animals, there are no studies on the therapeutic feasibility of lymphadenectomy, which is believed to be palliative in the reported patient, owing to the fact that it is a tubulopapillary carcinoma with different foci of lymph node metastases. Otherwise, lymphadenectomy enabled a better definition of the prognosis and proved to be an important tool for staging.

Identification of the iliac lymph node was possible due to intrauterine lymphatic mapping, according to the technique described by Justino et al. [8], who observed that the chain of iliac lymph nodes receives a substantial part of the drainage of the uterine horns. Differing from the work of Justino et al. [8], methylene blue was used as a lymphatic dye in this patient, which also allowed the successful localization and subsequent excision of the iliac lymph node.

There are several methods of sentinels lymph nodes mapping. Among the existing dyes, isosulfan blue (more used in Europe), patent blue (more used in Brazil and the United States), and at a lower frequency, methylene blue [3] are the most used. However, other markers have already been used in dogs, such as hemosiderin [15], technetium [14], iopamidol [16], fluorescein [18] and, in humans, indocyanine green [11]. The use of methylene blue was chosen because it has been used in dogs, with excellent results in the lymph nodes mapping, added to its ease of obtainment and low cost of application.

In spite of reports of hypersensitivity reactions with the use of methylene blue in canines, such as panniculitis and pigmentation of the inoculated region and other tissues, it is recommended to use 1 to $2 \mathrm{~mL}$ of contrast per animal $[1,7,10,12,13]$. Such alterations were not observed in the reported patient; and the dose used, although inferior to those described by some authors, allowed adequate dyeing.

Therefore, it is concluded that in canines with breast neoplasms, it is important to perform lymphatic mapping to identify possible metastases in cellular tissues and to delimit regional lymph vessels and lymph nodes, thus facilitating the surgical removal of these structures with safety margin. The report also shows that ovariohysterectomy and pelvic lymphadenectomy may present considerable importance in the management of breast neoplasms in dogs. In addition, it is relevant to perform lymphadenectomy even for lymph nodes that are not infarcted or present macroscopic changes, since in this case there was already metastasis even in a lymph node of $4 \mathrm{~mm}$.

\section{MANUFACTURER}

${ }^{1}$ Injectcenter Manipulação de Produtos Farmacêuticos. Ribeirão Preto, SP, Brazil.

Declaration of interest. The authors report no conflicts of interest. The authors alone are responsible for the content and writing of the paper.

Funding. This research was supported by grants from National Counsil for Cientific and Technological Development (CNPq; 444045/2014-7 and 308019/2015-6).

\section{REFERENCES}

1 Beserra H.E. 2016. O. Linfonodo sentinela. In: Daleck C.R. \& de Dardi A.B. (Eds). Oncologia em cães e gatos. São Paulo: Roca, pp.128-132.

2 Branco A.W. \& Kondo W. 2007. Linfadenectomia por vídeo-laparoscopia no câncer de próstata. Revista brasileira de videocirurgia. 5(3): 121-127. 
3 Brenet O., Lalourcey L. \& Queinnec M. 2013. Hypersensitivity reactions to patent blue v in breast cancer surgery: a prospective multicentre study. Acta Anesthesiology Scandinava. 57(1): 106-117.

4 Castelo D., Figueiredo A. Parada B., Nunes P. \& Mota A. 2010. O papel da linfadenectomia pélvica nos doentes submetidos a prostatectomia radical. Acta urológica. (4): 17-27.

5 Cowell R.L., Dorsey K.E. \& Meinkoth J.H. 2003. Lymph node cytology. Veterinary Clinical North American Small Animal Practice. 33(1): 47-67.

6 de Nardi A.B., Ferreira T.M.M.R. \& Assunção K.A. 2016. Neoplasias mamárias. In: Daleck C.R. \& de Nardi A.B. (Eds). Oncologia em cães e gatos. São Paulo: Roca, pp.498-516.

7 Jeudy G. Louvier N., Rapennes T., Goujon E., Fraisse J., Dalac-Rat S. \& Collet E. 2008. Immediate patent blueinduced hypersensitivity during sentinel node detection: the value of cutaneous tests. Annales de Dermatologie et de Vénéréologie. 135(6): 461-465.

8 Justino R.C., Cardoso G.S., Trautwein L.G.C., Dessunti G.T., Oliveira D.V., Bernardes R. \& Martins M.I.M. 2014. Uterine lymphangiography: comparison of two methods for locating the medial iliac lymph node. Pesquisa Veterinária Brasileira. 34(11): 1121-1126.

9 Karayannopoulou M., Kaldrymidou E., Constantinidis T.C. \& Dessiris A. 2005. Histological grading and prognosis in dogs with mammary carcinomas: application of a human grading method. Journal of Comparative Pathology. 133(4): 246-252.

10 Maranhão M.V.M., Nóbrega D.K.A, Anunciação C.E.C., Maia B.A.B. \& Mariano P.V.D. 2016. Allergic reaction to patent blue dye in breast surgery - case report. Brazilian Journal of Anesthesiology. 66(4): 433-436.

11 Miyashiro I., Kishi K., Yano M., Tanaka K., Motoori M., Ohue M., Ohigashi H., Takenaka A., Tomita Y. \& Ishikawa O. 2011. Laparoscopic detection of sentinel node in gastric cancer surgery by indocyanine green fluorescence imaging. Surgical Endoscopy. 25(5): 1672-1676.

12 Patsikas M.N., Karayannopoulou M., Kaldrymidoy E., Papazoglou L.G., Papadopoulou P.L., Tzegas S.I., Tziris N.E., Kaitzis D.G., Dimitriadis A.S. \& Dessiris A.K. 2006. The lymph drainage of the neoplastic mammary glands in the bitch: a lymphographic study. Anatomia, histologia e embryologia. 35(4): 228-234.

13 Pereira C.T., Rahal S.C., de Carvalho Balieiro J.C. \& Ribeiro A.A. 2003. Lymphatic drainage on healthy and neoplasic mammary glands in female dogs: can it really be altered? Anatomia, histologia, embryologia. 32(5): 282-290.

14 Pinheiro L.G.P., Moraes M.O., Soares A.H., Lopes A.J.T., Naguére M.A.S.P., Gondim F.A.L., Brandão C.B., Nascimento D.C.H., Soares J.P.H. \& Silva J.M.M. 2003. Estudo experimental de linfonodo sentinela na mama da cadela com azul patente e tecnécio tc99. Acta Cirúrgica Brasileira. 18(6): 545-552.

15 Pinheiro L.G.P., Oliveira Filho R.S., Vasques P.H.D., Filgueira P.H.O., Aragão D.H.P., Barbosa P.M.E., Beserra H.E.O. \& Cavalcante R.V. 2009. Hemosiderin. A new marker for sentinel lymph node identification. Acta Cirúrgica Brasileira. 24(6): 432-436.

16Suga K., Karino Y., Fujita T., Okada M., Kawakami Y., Ueda K., Yuan Y. \& Matsunaga N. 2007. Cutaneous drainage lymphatic map with interstitial multidetector-row computed tomographic lymphography using iopamidol: preliminary results. Lymphology. 40(2): 63-73.

17 Wainstein A.J.A., Barbosa L.C.C.S., Kansaon M., Salomé M. \& Drummond-Lage A.P. 2015. Advanced malignant melanoma during pregnancy: technical description of sentinel lymph node biopsy followed by radical lymph node dissection. Revista Brasileira de Saúde Materna Infantil. 15(4): 447-450.

18 Wells S., Bennett A., Walsh P., Owens S. \& Peauroi J. 2006. Clinical usefulness of intradermal fluorescein and patent blue violet dyes for sentinel lymph node identification in dogs. Veterinary and Comparative Oncology. 4(2): 114-122. 